13

\title{
Определение толщин и визуализация ионообменных волноводов в стеклах методом растровой электронной микроскопии
}

\author{
(С) А.И. Лихачев, А.Н. Нащекин, Р.В. Соколов, С.Г. Конников \\ Физико-технический институт им. А.Ф. Иофрфе РАН, \\ 194021 Санкт-Петербург, Россия \\ e-mail: Lihachev@mail.ioffe.ru
}

(Поступило в Редакцию 18 июня 2018 г. В окончательной редакции 21 сентября 2018 г.)

\begin{abstract}
Методами растровой электронной микроскопии и рентгеноспектрального микроанализа показано формирование в стеклах марки К8 в результате ионного обмена приповерхностного слоя с градиентом концентрации серебра и натрия. В режиме вторичных электронов визуализированы слои, обогащенные ионами серебра, с различной толщиной в зависимости от времени проведения ионного обмена из расплава серебра. Данные по толщине слоя, обогащенного серебром, измеренные методом РЭМ, хорошо коррелируют с расчетом, полученным из уравнения диффузии для серебра в стекле. Используя картирование элементного состава по поперечному сечению стекла, показана зависимость концентрации серебра от глубины диффузии. Присутствие слоя с градиентом концентрации серебра приводит к формированию градиентного волновода. Обнаружены дискретные пики на профилях концентрации серебра, обусловленные особенностями взаимной диффузии ионов натрия и серебра в стеклах.
\end{abstract}

DOI: 10.21883/JTF.2019.03.47185.243-18

\section{Введение}

В последние годы стекла со сформированными в их приповерхностном слое оптическими волноводами находят широкое применение в современной интегральной оптике [1], фотонике [2], а также биосенсорике [3]. Одним из основных воспроизводимых методов формирования волноводов в стеклах является метод ионного обмена в расплаве серебра [4], когда за счет термодиффузии ионы серебра вводятся в стекло на требуемую глубину. Далее обработанные таким образом стекла могут использоваться для синтеза (восстановления) серебряных наночастиц на их поверхности [5]. Присутствие ионов серебра в приповерхностном слое стекла приводит к изменению показателя преломления и образованию волновода [6]. В ходе ионного обмена, например, в расплаве $\mathrm{AgNO}_{3}: \mathrm{NaNO}_{3}$ ионы $\mathrm{Ag}$ замещают ионы Na. Глубина диффузии зависит от температуры и времени ионного обмена, а также от концентрации $\mathrm{AgNO}_{3}$ в расплаве [7]. В работах [8,9] было продемонстрировано формирование ионообменного волновода в приповерхностных слоях стекол и исследованы зависимость концентрации $\mathrm{Ag}$ в стекле и изменения показателя преломления от глубины диффузии в различных режимах ионного обмена. Измерение концентрации проводили методом рентгеноспектрального микроанализа (РСМА) в растровом электронном микроскопе. При этом в силу физических ограничений данный метод не может обеспечить пространственную точность измерений лучше $0.5 \mu \mathrm{m}$. В связи с этим более перспективным методом оценки толщины сформированного волновода представляется традиционный метод растровой электронной микроскопии (РЭМ) в режиме детектирования вторичных электронов (ВЭ), который обладает высоким пространственным разрешением благодаря малому размеру электронного пучка. Это особенно важно, когда речь идет о волноводах толщиной в единицы микрон. Кроме того, возможность проведения РСМА параллельно с получением электронно-микроскопических изображений позволяет более полно характеризовать исследуемые структуры. Целями настоящей работы было исследование стекол с ионообменными волноводами и их визуализация методами РЭМ и РСМА в режиме картирования и изучение влияния температуры ионного обмена на толщину волноводного слоя.

\section{Образцы и методика эксперимента}

В экспериментах были использованы стекла марки К8 с полированной поверхностью. Ввод ионов серебра в приповерхностные слои стекла осуществлялся методом ионного обмена. Подготовленные стекла помещались в керамические ванночки, содержащие традиционный для этой процедуры расплав $\mathrm{AgNO}_{3}(5 \mathrm{~mol} . \%): \mathrm{NaNO}_{3}$ $(95 \mathrm{~mol} \%$ ) и устанавливались в печь при температуре $355^{\circ} \mathrm{C}$ на различное время.

В работе была использована электрическая печь с программным управлением, построенная на основе резистивного нагревательного элемента и оснащенная тройным термоэкраном, обеспечивающим равномерное распределение тепла по всему рабочему объему. Максимальная рабочая температура составляет $450^{\circ} \mathrm{C}$.

Были изготовлены образцы с временем ионного обмена 15, 30, 45 и $60 \mathrm{~min}$. Далее делались поперечные сколы образцов, которые затем исследовались при помощи растрового электронного микроскопа JSM 7001F (JEOL, Japan), оснащенного системой энергодисперсионного (ЭДС) PCMA INCA PentaFETx (Oxford Instruments, 
England). Визуализация толщины волновода реализована в режиме картирования ЭДС по площади сечения волновода, после чего проводилось усреднение для построения профилей диффузии ионов серебра и натрия по глубине. Каждая карта представляет собой накопленный и усредненный набор из 15 кадров, что позволяет сушественно улучшить соотношение сигнал/шум.

\section{Экспериментальные результаты и обсуждение}

На рис. 1 приведено изображение скола образца (время ионного обмена $15 \mathrm{~min}$ ), полученное на растровом электронном микроскопе в режиме вторичных электронов. Формирование контраста обусловлено особенностями зарядки облучаемой электронами области: слой стекла без серебра заряжается отрицательно, приводя к более светлому контрасту по сравнению с более проводящей областью, обогащенной ионами серебра, избыточные заряды из которой стекают на землю. Результаты оценки толщин волноводов для остальных времен ионного обмена приведены на рис. 2 (кривая 2). По контрасту ВЭ можно определить наличие волноводного слоя, обусловленного диффузией ионов $\mathrm{Ag}$, и оценить его толщину, которая составила $1.67 \mu \mathrm{m}$ для $15 \mathrm{~min}$, $2.31 \mu \mathrm{m}$ для $30 \mathrm{~min}, 2.83$ для $45 \mathrm{~min}$ и $3.08 \mu \mathrm{m}$ для $60 \mathrm{~min}$ ионного обмена. Контраст между волноводным слоем и объемом стекла вызван перераспределением заряда при облучении электронным пучком, вследствие наличия в волноводном слое ионов $\mathrm{Ag}$, которые обеспечивают лучший сток заряда, уменьшая выход ВЭ.

Для численной оценки глубины диффузии ионов Ag в результате ионного обмена необходимо воспользоваться уравнением диффузии

$$
\frac{\partial C}{\partial t}=D \frac{\partial^{2} C}{\partial y^{2}},
$$

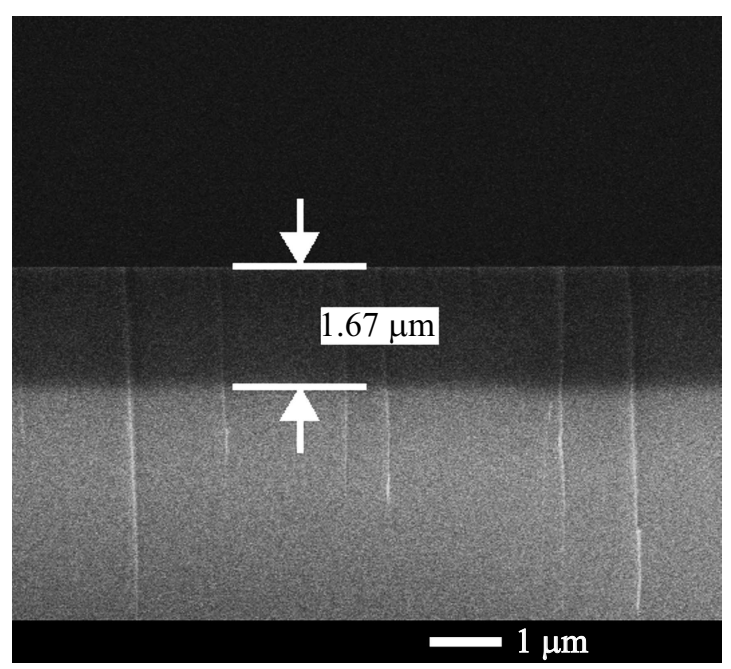

Рис. 1. РЭМ-изображение в режиме вторичных электронов образца с временем инного обмена $15 \mathrm{~min}$.

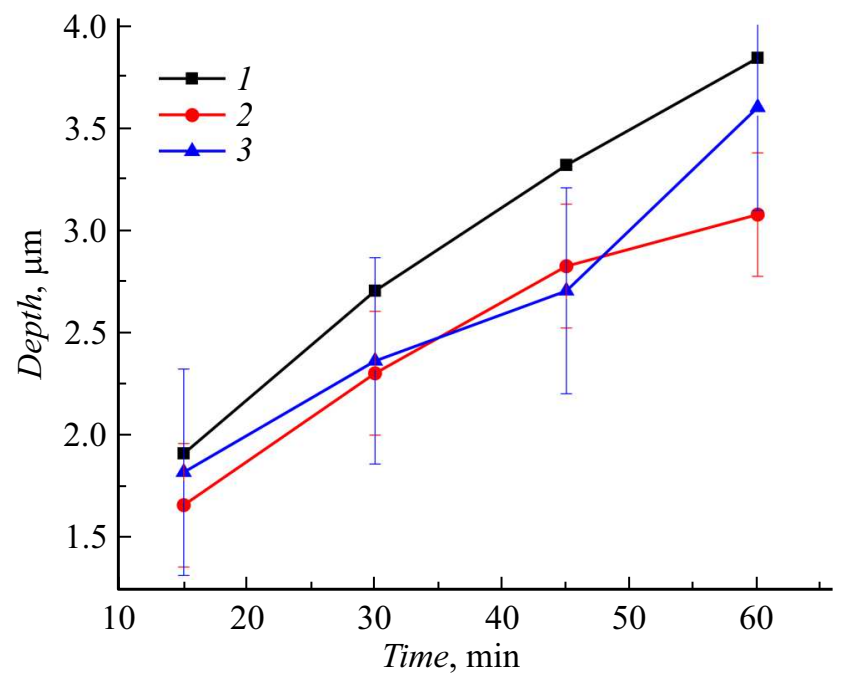

Рис. 2. Зависимость глубины диффузии ионов $\mathrm{Ag}$ при разном времени ионного обмена: 1 - численная оценка глубины диффузии, 2 - измерение в режиме ВЭ, 3 - измерение в режиме картирования по поперечному стечению стекла.

где $D$ - коэффициент диффузии, $y-$ глубина диффузии. Это уравнение имеет решение вида [4]:

$$
C(y, t)=C_{0} \operatorname{erfc}\left(\frac{y}{2 \sqrt{D t}}\right)
$$

где $C_{0}-$ константа. Было использовано значение $D=2.52 \cdot 10^{-15} \mathrm{~m}^{2} / \mathrm{c}[10]$. Поскольку в эксперименте по ионному обмену можно считать, что на поверхности подложки находится расплав металла, являющийся условно бесконечным источником серебра, то граничные условия можно записать в виде $C(0, t)=1 \Rightarrow C_{0}=1$. На рис. 2 представлены зависимости глубины диффузии ионов Ag от времени ионного обмена, построенные на основе результатов измерений и на основе численной оценки из (2). Из рисунка видно, что обе зависимости ведут себя схожим образом, а расхождение между численной оценкой и измеренными значениями глубины диффузии могут быть связаны с тем, что при низком содержании серебра в стекле контраст, полученный в режиме ВЭ в РЭМ, между стеклом с ионами Ag и без них становится неразличимым. Эта тенденция растет с увеличением времени ионного обмена, что обусловлено, по-видимому, диффузным размытием границы. Кроме того, негативное влияние на контраст изображения оказывают зарядовые эффекты в стекле.

Метод РСМА в режиме картирования позволяет не только определить с точностью до десятых долей процента присутствие того или иного химического элемента, но также получить его распределение по глубине. Пример карт распределения серебра и натрия для случая $30 \mathrm{~min}$ ионного обмена по поперечному сечению волноводного слоя представлен на рис. 3 Из полученных карт путем статистической обработки были построены профили распределения Ag для каждого образца в 


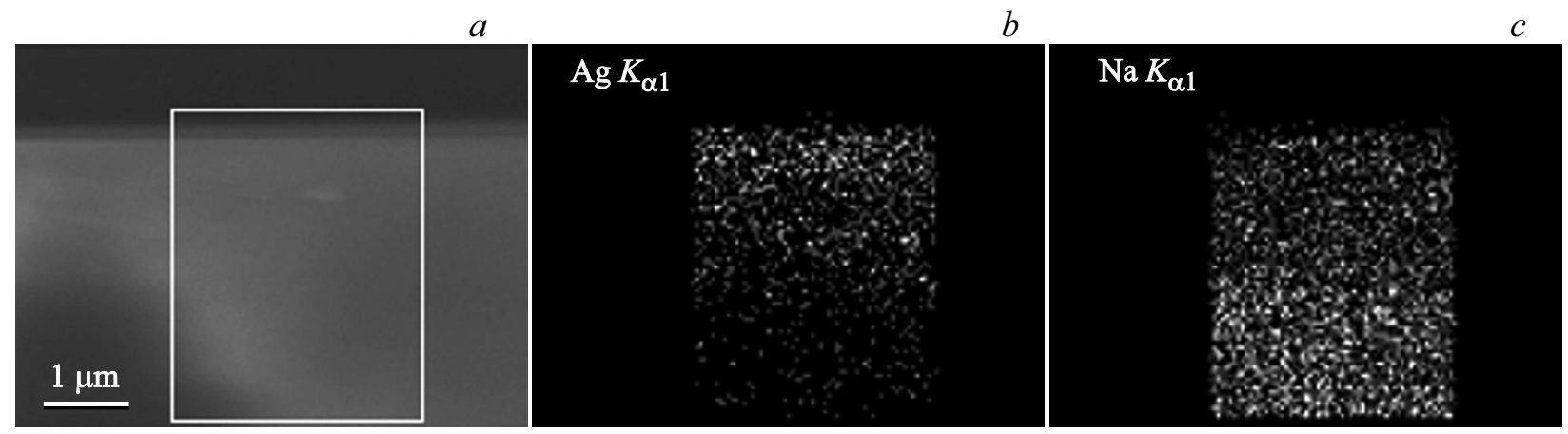

Рис. 3. Пример карт распределения $\mathrm{Ag}$ и Na для случая $30 \mathrm{~min}$ ионного обмена: $a-$ РЭМ-изображение в режиме ВЭ с выделенной областью накопления карт, $b$ - карта распределения $\mathrm{Ag}, c$ - карта распределения $\mathrm{Na}$.

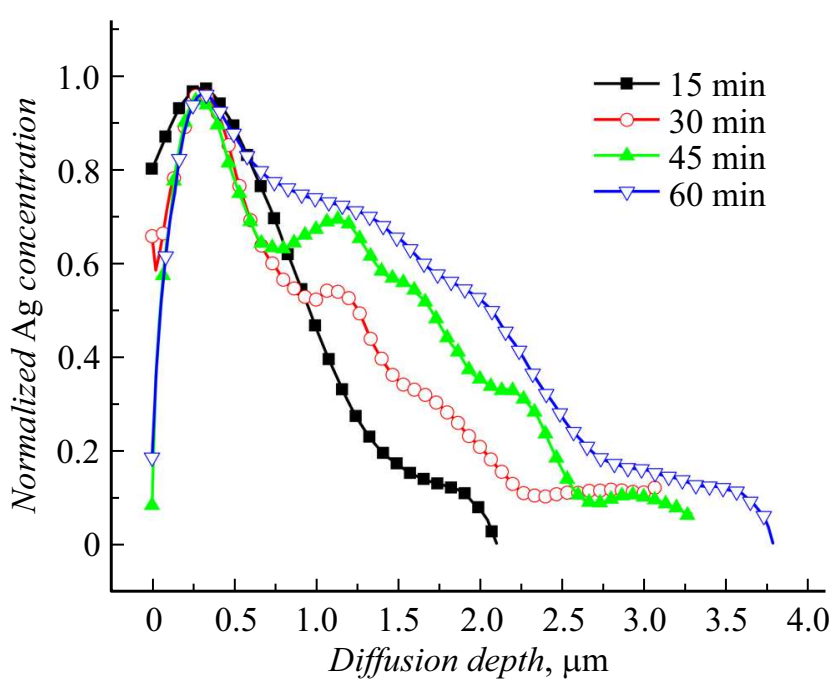

Рис. 4. Профиль распределения Ag в зависимости от глубины диффузии.

зависимости от глубины диффузии (рис. 4), нормированные на максимальное значение. Профили распределения серебра, полученные для всех режимов ионного обмена, представлены на рис. 4. Данные о глубине диффузии серебра удобно взять из ненормированных профилей диффузии на уровне 0.1 (см. рис. 2, кривая 3). Видно, что глубина диффузии, оцененная из метода картирования, хорошо коррелирует с численной оценкой из уравнения диффузии, а также глубиной диффузии, измеренной в режиме ВЭ, с учетом погрешности, обусловленной размерами области взаимодействия электронного пучка с образцом при выполнении РСМА. Кроме того, на профилях хорошо заметны сформированные дискретные пики концентрации серебра. Природа образования этих пиков связана с различием коэффициентов диффузии ионов натрия и серебра в стеклах. Видно, что с ростом времени ионного обмена сформированные на ранних стадиях концентрационные пики (при 15 и $30 \mathrm{~min}$ ) начинают расплываться (60 min).
Как было установлено в [7], наличие в приповерхностном слое стекла ионов серебра приводит к изменению показателя преломления, который связан с концентрацией серебра зависимостью вида

$$
n(x)=n_{0}+\Delta n_{\max } C(x),
$$

где $n_{0}$ - показатель преломления исходного стекла, $C(x)$ - нормированная зависимость концентрации ионов серебра от глубины, $\Delta n_{\max }$ - изменение показателя преломления на границе стекло-расплав. Исходя из полученных данных (рис. 4) можно сделать вывод о том, что в исследованных структурах в результате ионного обмена в приповерхностной области стекла сформировался слой с более высоким относительно окружающего объема стекла показателем преломления, т. е. образуется планарный волновод с градиентом показателя преломления и толщиной до нескольких микрон.

\section{Заключение}

В результате проведенных исследований методами РЭМ и РСМА было экспериментально показано формирование в стеклах К8 планарного ионообменного волновода с градиентом концентрации серебра и натрия, что приводит к градиенту показателя преломления. Для определения параметров этого слоя были использованы методы РЭМ и РСМА в режиме картирования по сколу структуры, что позволило визуализировать зависимость концентрации серебра в стекле от глубины диффузии. На профилях концентрации серебра обнаружены дискретные пики, природа образования которых связана с особенностями взаимной диффузии ионов натрия и серебра в стеклах. Также было показано, что экспериментальные данные по глубине диффузии серебра при различном времени ионного обмена хорошо коррелируют с расчетом, полученным из уравнения диффузии. Наличие слоя с градиентом концентрации Ag, согласно [7], приводит к формированию волновода, толщину которого можно контролировать, выбирая соответствующие режимы ионного обмена, в частности, температуру. 
Это позволяет создавать в стеклах планарные волноводы заданной толщины, которые находят все более широкое применение в современной интегральной оптике, фотонике, а также биосенсорике.

Электронно-микроскопические исследования выполнены с использованием оборудования федерального ЦКП „Материаловедение и диагностика в передовых технологиях“, поддержанного Минобрнауки России (Уникальный идентификатор проекта RFMEFI62117X0018).

\section{Список литературы}

[1] Sakamaki Y., Shikama K., Ikuma Y., Suzuki K. // Opt. Express. 2017. Vol. 25. N 17. P. 19946-19954.

[2] Zhou J., Du Q., Xu P., Zhao Y., Lin R., Wu Y., Zhang P., Zhang $W$., Shen $X$. // IEEE J. Sel. Top. Quantum Electron. 2018. Vol. 24. N 4.

[3] Wijaya E., Lenaerts C., Maricot S., Hastanin J., Habraken S., Vilcot J.-P., Boukherroub R., Szunerits S. // Current Opinion Sol. Stat. Mater. Sci. 2011. Vol. 15. N 5. P. 208-224.

[4] Tervonen A., West B.R., Honkanen S. // Opt. Eng. 2011. Vol. 50. P. 071107.

[5] Образиов П.А., Нащекин А.В., Никоноров Н.В., Сидоров А.И., Панфилова А.В., Брунков П.Н. // ФТТ. 2013. Т. 55. Вып. 6. С. 1180-1186.

[6] Егоров В.И., Нащекин А.В., Образцов П.А., Сидоров А.И., Брунков П.Н. // Оптич. журн. 2013. Т. 80. № 3. С. 61-67.

[7] Журихина В.В., Петров М.И., Соколов К.С., Шустова О.В. // ЖТФ. 2010. Т. 80. Вып. 10. С. 58-63.

[8] Подвязный А.А., Свистунов Д.В. // Письма в ЖТФ. 2003. Т. 29. Вып. 11. С. 35-40.

[9] Blondeau J.-P., Véron O. // Opt. Mat. 2011. Vol. 34. N 1. Р. 278-286.

[10] Таблицы физических величин / Справочник под ред. И.К. Кикоина. М.: Атомиздат, 1976. 